\title{
Geosphere
}

Supporting Information for

\section{Southern Chile Crustal Structure from Teleseismic Receiver Functions: Responses to Ridge Subduction and Terrane Assembly of the Patagonian Microplate}

\author{
E. E. Rodriguez ${ }^{1 *}$ and R. M. Russo ${ }^{1}$ \\ ${ }^{1}$ Department of Geological Sciences, University of Florida, Gainesville, FL, 32611 \\ * Now at: Department of Geosciences, University of Arizona, Tucson, AZ, 85721
}

\section{Contents of this file}

Tables S1 to S2

Figures S1 to S16

\section{Introduction}

This supporting material includes the receiver function stacks, $H-k$ grid search and bootstrapping results for each station, reported in tables and with their individual grid search result figures. 
Rodriguez, E.E. and Russo, R.M., 2019, Southern Chile crustal structure from teleseismic receiver functions:

Responses to ridge subduction and terrane assembly of Patagonia: Geosphere, v. 15, https://doi.org/10.1130/GES01692.1. Supplemental material: https://doi.org/10.1130/GES01692.S1

Table S1. $H-k$ and $H-k$ bootstrap results for the CRSP network (3 letter coded).

\begin{tabular}{|c|c|c|c|c|c|c|c|c|}
\hline Station & Lat. $\left(^{\circ}\right)$ & Lon. $\left(^{\circ}\right)$ & $\begin{array}{l}\text { Elevation } \\
\text { (m) }\end{array}$ & $H$ value $(\mathrm{km})$ & $k$ value & Bootstrap $H$ value $(\mathrm{km})$ & Bootstrap $k$ value & RFs \\
\hline $\mathrm{AGU}$ & -45.1508 & -73.5089 & 49.6 & 43.1 & 1.79 & $42.7+/-4.2$ & $1.80+/-0.08$ & 7 \\
\hline $\mathrm{AMG}$ & -44.7475 & -72.2136 & 352 & 40.6 & 1.73 & $38.9+/-6.2$ & $1.76+/-0.10$ & 6 \\
\hline BAK & -47.1840 & -71.9735 & 563.7 & 42.7 & 1.68 & $41.7+/-4.9$ & $1.71+/-0.09$ & 11 \\
\hline BMU & -46.4358 & -72.6720 & 360.7 & 32 & 1.84 & $36.6+/-4.7$ & $1.75+/-0.11$ & 19 \\
\hline CAL & -45.4794 & -71.6035 & 778.2 & 24.9 & 1.68 & $27.4+/-4.0$ & $1.73+/-0.08$ & 29 \\
\hline $\mathrm{CHB}$ & -45.4616 & -71.8165 & 57.3 & 31 & 1.67 & $42.9+/-2.9$ & $1.78+/-0.06$ & 4 \\
\hline $\mathrm{CHC}$ & -46.5415 & -71.7351 & 347.1 & 31.3 & 1.77 & $43.9+/-9.5$ & $1.78+/-0.10$ & 20 \\
\hline $\mathrm{CHN}$ & -46.9179 & -72.7351 & 498 & 32.9 & 1.79 & $32.2+/-2.2$ & $1.76+/-0.06$ & 8 \\
\hline $\mathrm{COC}$ & -47.2560 & -72.5920 & 177.2 & 32.9 & 1.79 & $35.0+/-6.2$ & $1.73+/-0.10$ & 20 \\
\hline $\mathrm{COY}$ & -45.5639 & -72.0911 & 390.2 & 31.6 & 1.62 & $28.8+/-4.0$ & $1.73+/-0.07$ & 9 \\
\hline CTS & -44.7339 & -72.6795 & 52.3 & 41.2 & 1.61 & $39.2+/-3.4$ & $1.71+/-0.13$ & 9 \\
\hline FNL & -46.5516 & -72.2219 & 256.2 & 42.3 & 1.64 & $39.5+/-3.9$ & $1.64+/-0.08$ & 4 \\
\hline HOP & -46.7269 & -75.4333 & 72 & 27.1 & 1.64 & $27.5+/-3.5$ & $1.65+/-0.05$ & 9 \\
\hline HUD & -46.0505 & -72.6899 & 473.3 & 36 & 1.77 & $35.8+/-3.8$ & $1.77+/-0.06$ & 6 \\
\hline HUM & -45.5577 & -73.9591 & 88.2 & 38.2 & 1.84 & $39.2+/-4.9$ & $1.78+/-0.10$ & 5 \\
\hline IBJ & -44.6861 & -73.9899 & 70.3 & 48.4 & 1.89 & $43.6+/-8.0$ & $1.84+/-0.09$ & 8 \\
\hline $\mathrm{IMG}$ & -44.4017 & -73.0914 & 35.2 & 33 & 1.7 & $35.8+/-5.7$ & $1.67+/-0.05$ & 9 \\
\hline ISM & -45.9276 & -73.8312 & 40.9 & 27.8 & 1.92 & $28.6+/-4.7$ & $1.92+/-0.05$ & 13 \\
\hline JEI & -46.8318 & -71.9951 & 877.7 & 32.6 & 1.71 & $32.7+/-3.5$ & $1.71+/-0.08$ & 20 \\
\hline LPL & -45.3198 & -72.7075 & 104.6 & 33 & 1.79 & $36.2+/-6.6$ & $1.77+/-0.10$ & 6 \\
\hline LRC & -47.2829 & -72.8655 & 141.6 & 36.2 & 1.71 & $38.4+/-4.1$ & $1.71+/-0.08$ & 5 \\
\hline LSR & -46.6615 & -73.8586 & 55.3 & 26.8 & 1.64 & $28.4+/-4.7$ & $1.64+/-0.04$ & 29 \\
\hline LTQ & -46.64192 & -72.7981 & 470 & 31.8 & 1.82 & $32.9+/-4.7$ & $1.81+/-0.06$ & 37 \\
\hline MEL & -43.8555 & -73.7427 & 122.3 & 56.5 & 1.77 & $55.3+/-5.0$ & $1.77+/-0.07$ & 27 \\
\hline MRF & -46.7256 & -72.9363 & 298.5 & 44 & 1.66 & $39.0+/-6.3$ & $1.66+/-0.06$ & 18 \\
\hline NWM & -46.4409 & -74.8939 & 57.3 & 29.6 & 1.63 & $29.2+/-0.9$ & $1.64+/-0.02$ & 4 \\
\hline
\end{tabular}


Rodriguez, E.E., and Russo, R.M., 2019, Southern Chile crustal structure from teleseismic receiver functions:

Responses to ridge subduction and terrane assembly of Patagonia: Geosphere, v. 15, https://doi.org/10.1130/GES01692.1. Supplemental material: https://doi.org/10.1130/GES01692.S1

\begin{tabular}{ccccccccc} 
PDR & -46.3024 & -71.8608 & 398.8 & 51.5 & 1.77 & $53.0+/-2.3$ & $1.75+/-0.03$ & 4 \\
PLM & -46.1773 & -74.4318 & 85.7 & 32.7 & 1.86 & $36.0+/-5.2$ & $1.82+/-0.09$ & 9 \\
PYU & -44.3233 & -72.5552 & 51.2 & 45 & 1.68 & $41.5+/-5.3$ & $1.72+/-0.09$ & 15 \\
RCS & -44.4962 & -71.3168 & 817.8 & 28.5 & 1.61 & $28.1+/-5.0$ & $1.65+/-0.05$ & 8 \\
RMB & -43.7734 & -72.9548 & 46.1 & 48.1 & 1.72 & $44.4+/-7.1$ & $1.73+/-0.02$ & 3 \\
RMG & -45.9068 & -72.3212 & 388 & 34.7 & 1.85 & $36.6+/-3.9$ & $1.82+/-0.08$ & 9 \\
RPR & -46.2217 & -74.0101 & 45.6 & 29.2 & 1.8 & $33.9+/-5.7$ & $1.83+/-0.03$ & 12 \\
RRS & -47.4767 & -72.5414 & 45.6 & 37.7 & 1.7 & $34.8+/-4.6$ & $1.75+/-0.08$ & 21 \\
SAD & -46.7529 & -74.4598 & 68.1 & 32.1 & 1.62 & $33.8+/-6.8$ & $1.64+/-0.07$ & 14 \\
VCC & -46.1208 & -72.1607 & 367.3 & 50.8 & 1.83 & $47.7+/-7.4$ & $1.82+/-0.05$ & 48 \\
VMG & -45.1755 & -72.1426 & 214.9 & 33.8 & 1.74 & $34.7+/-3.8$ & $1.74+/-0.08$ & 29 \\
VOH & -48.4679 & -72.5615 & 302.4 & 38 & 1.62 & $36.7+/-4.9$ & $1.67+/-0.09$ & 18 \\
YNG & -47.9326 & -73.3285 & 81.3 & 37.9 & 1.61 & $34.8+/-4.6$ & $1.69+/-0.08$ & 16 \\
ALE** & -45.8105 & -74.1574 & 56.9 & & & & & \\
IML** & -45.2587 & -73.8046 & 59.2 & & & & & - \\
IVV** & -44.2725 & -73.7824 & 60.8 & & & & & - \\
\hline
\end{tabular}

**Short period stations 
Rodriguez, E.E and Russo, R.M., 2019, Southern Chile crustal structure from teleseismic receiver functions:

Responses to ridge subduction and terrane assembly of Patagonia: Geosphere, v. 15, https://doi.org/10.1130/GES01692.1. Supplemental material: https://doi.org/10.1130/GES01692.S1

Table S2. $H-k$ and $H-k$ bootstrapping results for the SEARCH network (4 letter coded).

\begin{tabular}{|c|c|c|c|c|c|c|c|c|}
\hline Station & Lat. $\left(^{\circ}\right)$ & $\operatorname{Lon}\left(^{\circ}\right)$ & $\begin{array}{c}\text { Elevation } \\
\text { (m) }\end{array}$ & $H$ value $(\mathrm{km})$ & $k$ value & Bootstrap $H$ value $(\mathrm{km})$ & Bootstrap $k$ value & RFs \\
\hline ALAC & -46.5063 & -73.0630 & 293 & 33.11 & 1.64 & $37.7+/-4.8$ & $1.66+/-0.08$ & 3 \\
\hline BAEX & -46.3067 & -73.5350 & 3 & 37.48 & 1.64 & $37.8+/-5.0$ & $1.66+/-0.08$ & 5 \\
\hline BARR & -45.7349 & -72.2063 & 414 & 42.49 & 1.86 & $42.8+/-5.5$ & $1.82+/-0.07$ & 9 \\
\hline BERT & -47.0198 & -72.8017 & 395 & 43.34 & 1.85 & $43.5+/-3.6$ & $1.87+/-0.03$ & 8 \\
\hline ELCO & -47.2538 & -72.5314 & 321 & 33.87 & 1.76 & $35.3+/-4.6$ & $1.75+/-0.09$ & 19 \\
\hline ELSA & -46.6068 & -72.7420 & 236 & 31.91 & 1.8 & $33.5+/-3.9$ & $1.80+/-0.06$ & 11 \\
\hline ENBA & -47.1348 & -72.0542 & 516 & 33.68 & 1.79 & $35.5+/-5.8$ & $1.79+/-0.08$ & 7 \\
\hline JARA & -46.5173 & -71.8459 & 230 & 42.49 & 1.64 & $43.3+/-4.3$ & $1.65+/-0.05$ & 7 \\
\hline JOSE & -46.7472 & -72.5432 & 328 & 46.92 & 1.63 & $44.5+/-4.5$ & $1.63+/-0.08$ & 27 \\
\hline JOVI & -46.5009 & -72.7216 & 268 & 32.41 & 1.8 & $36.6+/-5.9$ & $1.75+/-0.10$ & 16 \\
\hline LAJE & -46.8438 & -71.9977 & 868 & 38.73 & 1.6 & $37.8+/-5.9$ & $1.65+/-0.09$ & 7 \\
\hline LAMO & -45.8595 & -72.0510 & 640 & 31.53 & 1.79 & $34.8+/-5.6$ & $1.76+/-0.08$ & 24 \\
\hline $\mathrm{LAOH}$ & -48.5170 & -72.5967 & 252 & 39.79 & 1.93 & $40.2+/-1.5$ & $1.90+/-0.07$ & 5 \\
\hline LAPO & -45.702702 & -71.8333 & 833 & 33.9 & 1.84 & $35.6+/-5.4$ & $1.83+/-0.08$ & 23 \\
\hline LASN & -46.242352 & -72.0869 & 549 & 49.02 & 1.67 & $49.1+/-2.6$ & $1.66+/-0.05$ & 10 \\
\hline LATR & -45.667831 & -72.4130 & 292 & 35.29 & 1.8 & $37.1+/-4.0$ & $1.79+/-0.03$ & 10 \\
\hline LAVA & -47.700401 & -73.1443 & 42 & 31.37 & 1.86 & $34.6+/-6.0$ & $1.81+/-0.09$ & 17 \\
\hline LEVI & -46.34782 & -71.9336 & 478 & 34.88 & 1.79 & $38.5+/-4.2$ & $1.73+/-0.06$ & 16 \\
\hline LNEG & -46.57732 & -72.6423 & 157 & 32.65 & 1.79 & $33.5+/-4.5$ & $1.80+/-0.07$ & 6 \\
\hline LUNA & -45.882919 & -72.3299 & 292 & 49.2 & 1.87 & $46.9+/-4.5$ & $1.87+/-0.05$ & 4 \\
\hline MANE & -45.383831 & -71.9854 & 609 & 38.29 & 1.77 & $37.3+/-5.2$ & $1.77+/-0.07$ & 21 \\
\hline MANS & -46.14542 & -72.3880 & 358 & 39.55 & 1.88 & $40.0+/-4.9$ & $1.80+/-0.10$ & 14 \\
\hline MART & -46.836948 & -72.8004 & 216 & 34.94 & 1.82 & $36.0+/-5.1$ & $1.75+/-0.08$ & 11 \\
\hline MAYE & -48.26313 & -72.4265 & 404 & 33.11 & 1.8 & $33.6+/-4.2$ & $1.80+/-0.07$ & 15 \\
\hline MILI & -47.174919 & -71.8883 & 613 & 27.21 & 1.56 & $27.7+/-6.4$ & $1.62+/-0.10$ & 11 \\
\hline ODGE & -46.147419 & -73.7149 & 3 & 46.08 & 1.92 & $54.2+/-3.5$ & $1.78+/-0.06$ & 5 \\
\hline PALA & -46.295719 & -71.8321 & 425 & 44.41 & 1.61 & $42.0+/-4.3$ & $1.66+/-0.08$ & 12 \\
\hline PCEA & -45.67308 & -72.2212 & 372 & 35.58 & 1.83 & $38.4+/-4.9$ & $1.83+/-0.05$ & 29 \\
\hline
\end{tabular}


Rodriguez, E.E., and Russo, R.M., 2019, Southern Chile crustal structure from teleseismic receiver functions:

Responses to ridge subduction and terrane assembly of Patagonia: Geosphere, v. 15, https://doi.org/10.1130/GES01692.1. Supplemental material: https://doi.org/10.1130/GES01692.S1

\begin{tabular}{ccccccccc} 
PENI & -47.237572 & -72.3300 & 186 & 34.05 & 1.77 & $35.2+/-3.2$ & $1.78+/-0.06$ & 37 \\
PUAG & -45.167221 & -73.5133 & 3 & 29.82 & 1.55 & $29.2+/-2.0$ & $1.58+/-0.04$ & 8 \\
PUCH & -45.450081 & -72.7886 & 24 & 41.52 & 1.76 & $42.1+/-5.6$ & $1.71+/-0.05$ & 5 \\
TORT & -47.7941 & -73.5281 & 95 & 26.04 & 1.69 & $31.4+/-5.3$ & $1.76+/-0.08$ & 4 \\
TRAI & -46.3282 & -72.7708 & 352 & 40.16 & 1.82 & $42.0+/-4.6$ & $1.83+/-0.06$ & 6 \\
TRES & -47.4062 & -72.7119 & 405 & 30.01 & 1.9 & $33.7+/-5.2$ & $1.82+/-0.11$ & 13 \\
VERD & -46.5573 & -71.9521 & 465 & 33.06 & 1.86 & $36.7+/-6.2$ & $1.82+/-0.10$ & 4 \\
VIVI & -45.3606 & -72.4571 & 274 & 29.35 & 1.64 & $34.4+/-7.1$ & $1.69+/-0.08$ & 11 \\
QUIT** & -45.6527 & -73.2017 & 3 & & & & - \\
RIMA** & -45.3111 & -72.3269 & 629 & & & & - \\
\hline
\end{tabular}

** Noisy Stations 

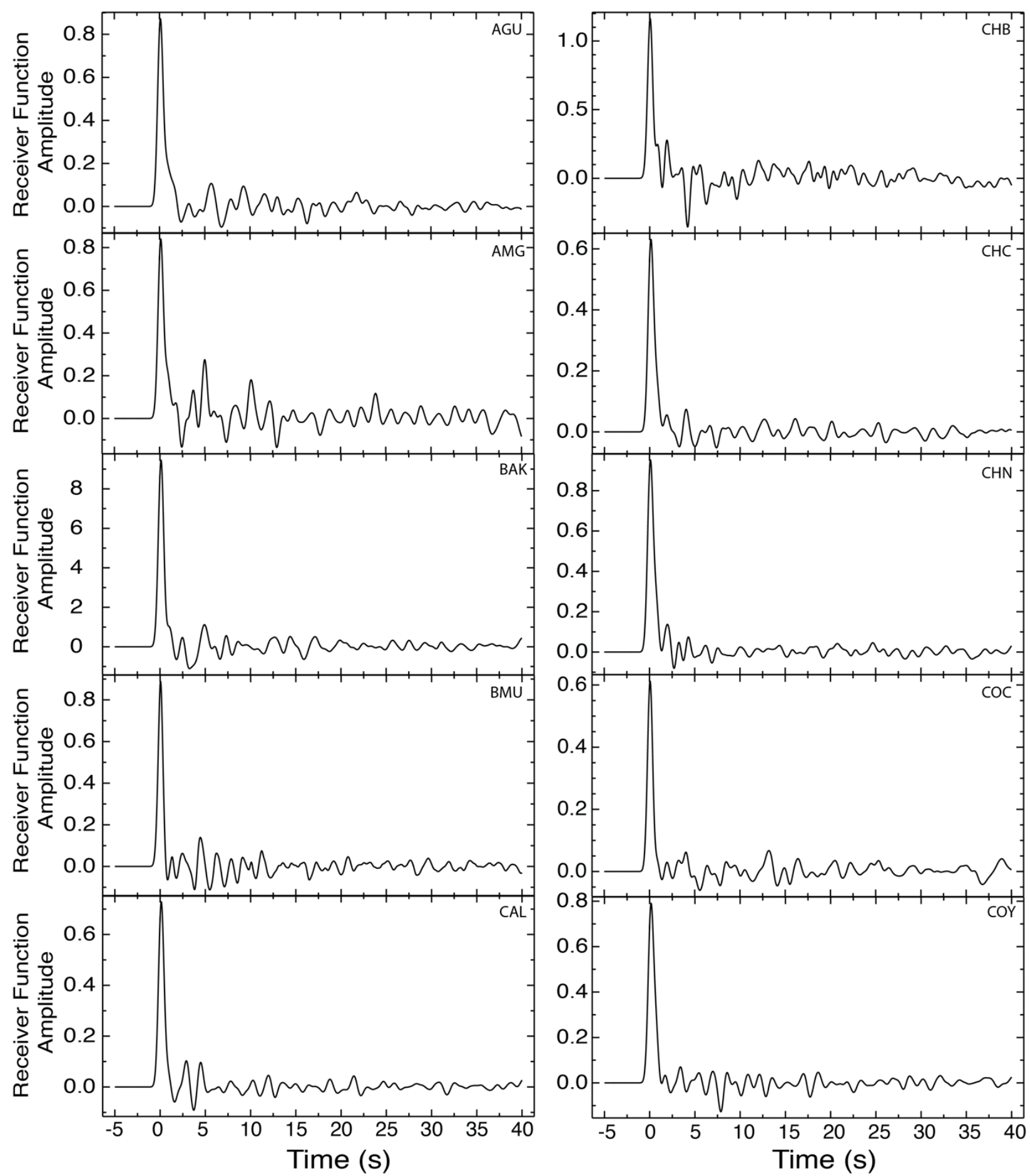

Figure S1. Receiver functions stacks of the CRSP network (Stations AGU - COY). Stations are denoted in right upper corner. The stacks include normal move-out corrections where stations were stacked by their P-arrival time. 

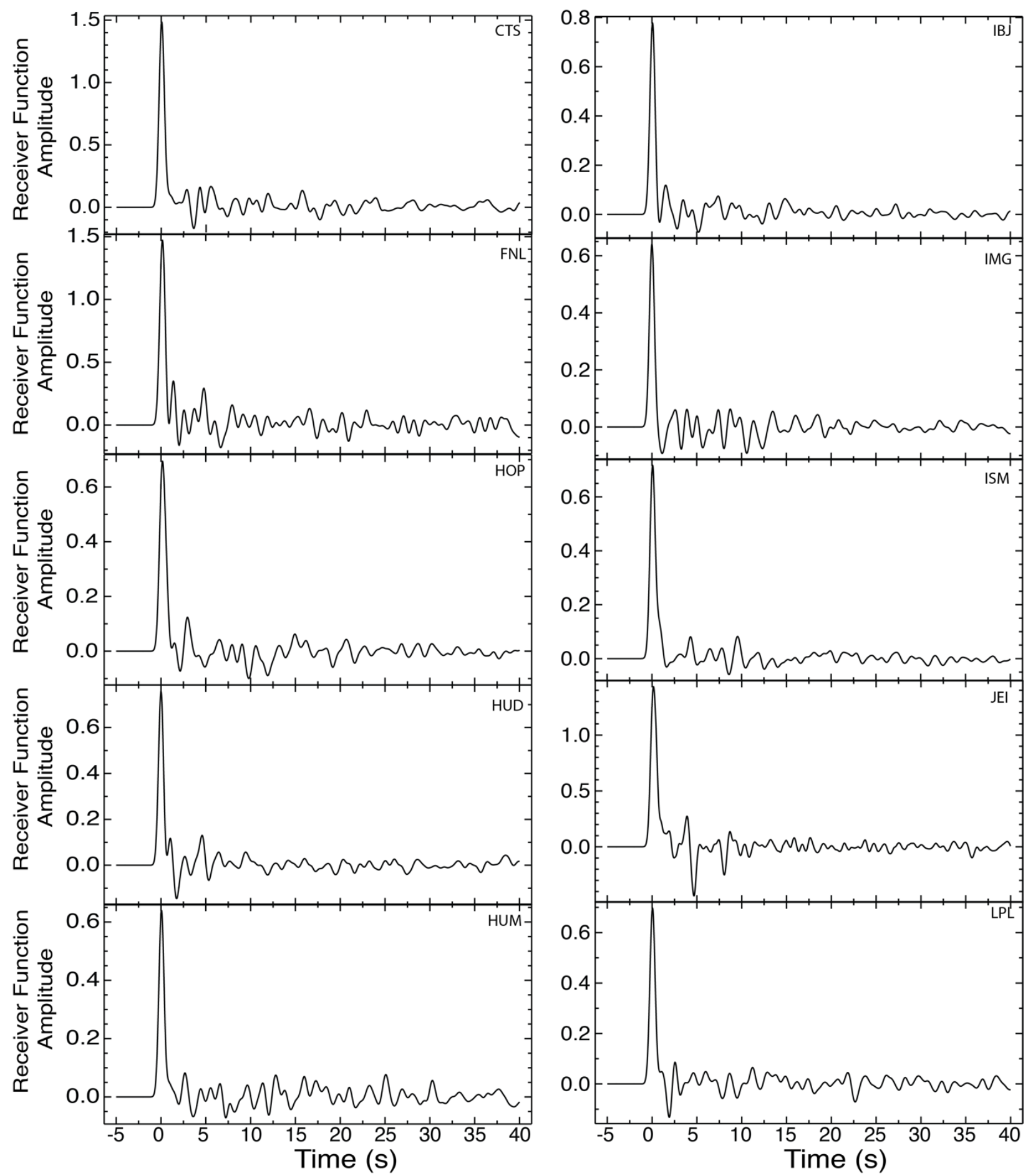

Figure S2. Receiver function stacks of the CRSP network (Stations CTS - LPL). Stations are denoted in right upper corner. 

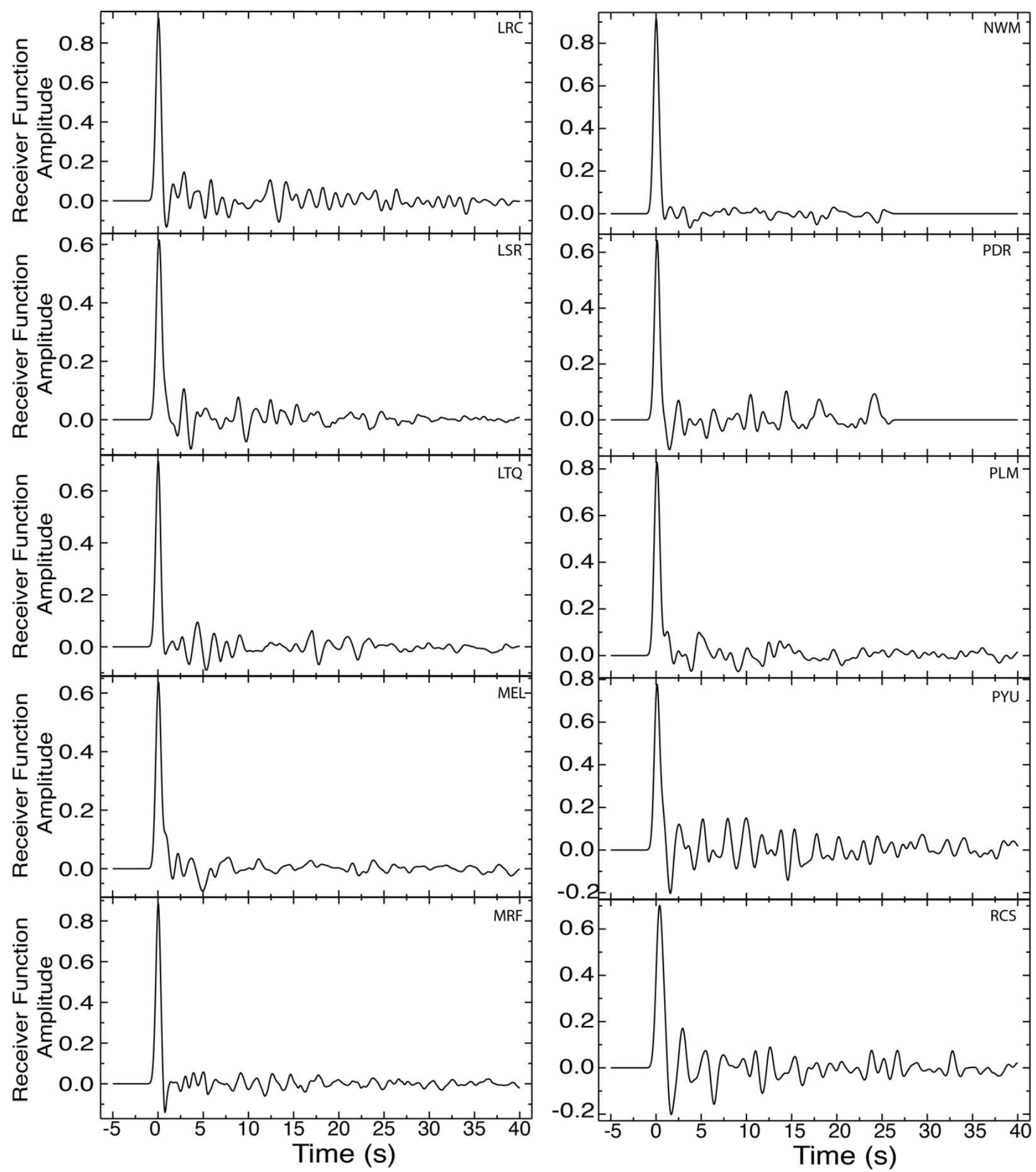

Figure S3. Receiver function stacks of the CRSP network (Stations LRC - RCS). Stations are denoted in right upper corner. 

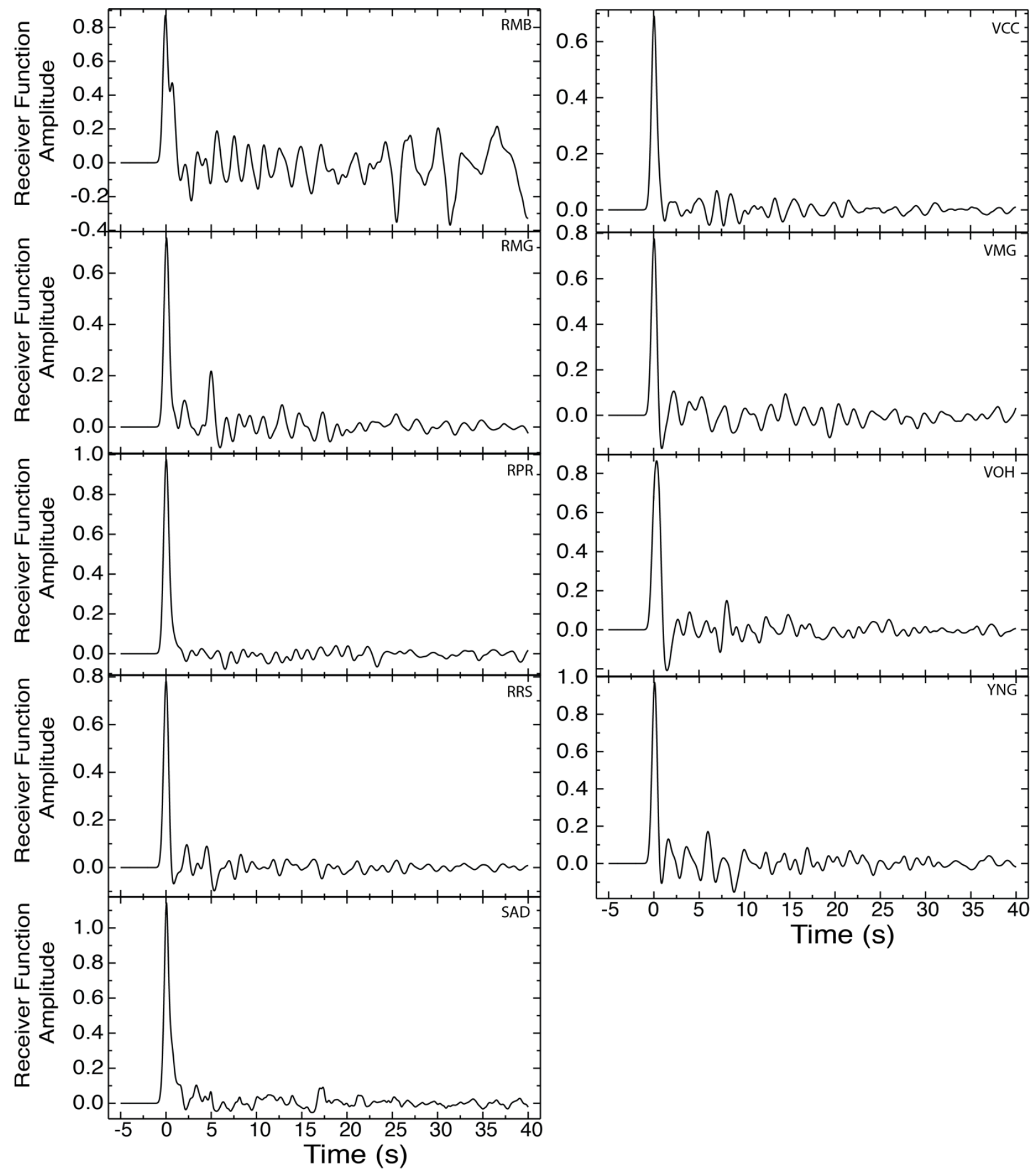

Figure S4. Receiver function stacks of the CRSP network (Stations RMB - YNG). Stations are denoted in right upper corner. 
Rodriguez, E.E., and Russo, R.M., 2019, Southern Chile crustal structure from teleseismic receiver functions:

Responses to ridge subduction and terrane assembly of Patagonia: Geosphere, v. 15, https://doi.org/10.1130/GES01692.1. Supplemental material: https://doi.org/10.1130/GES01692.S1
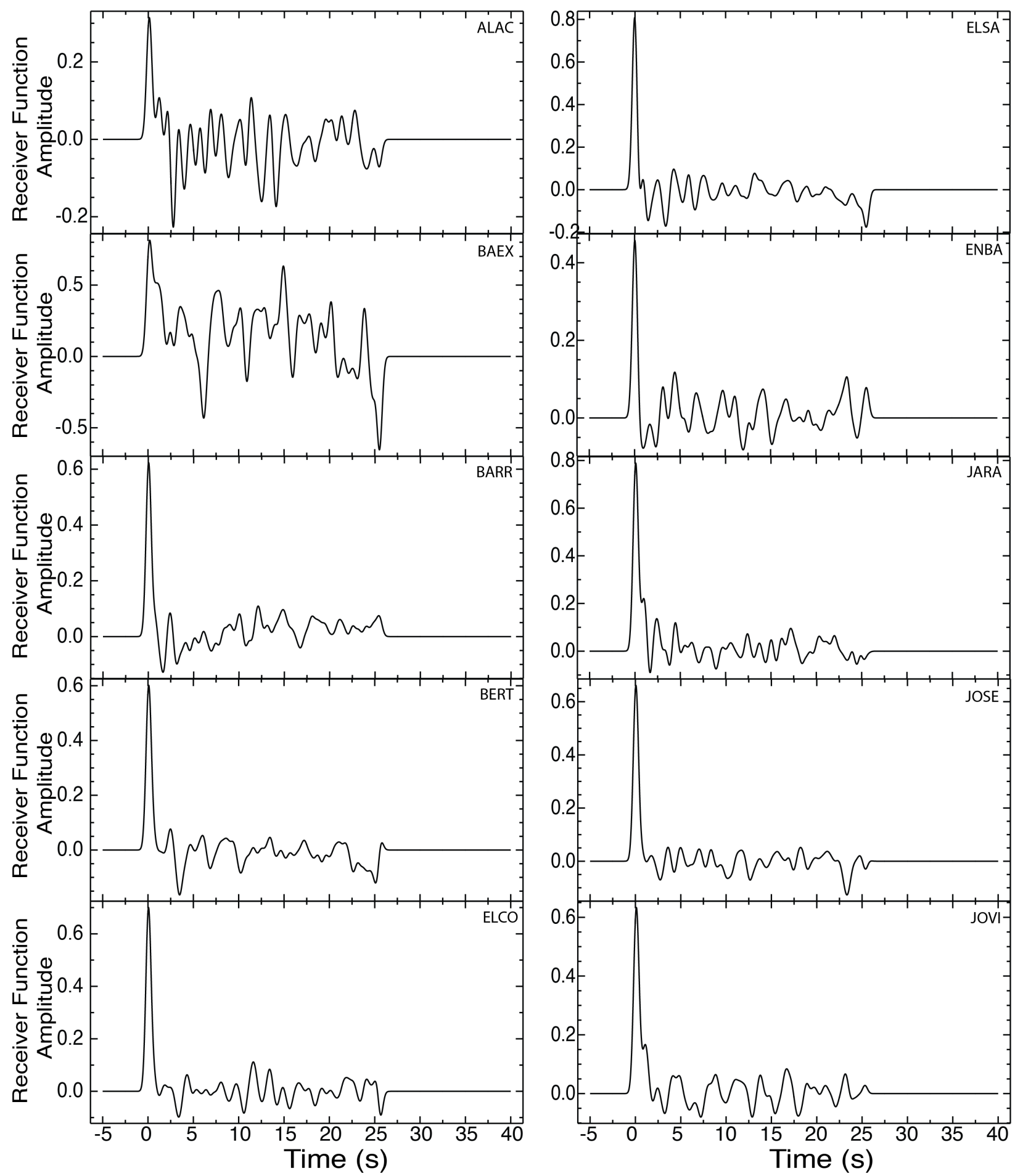

Figure S5. Receiver function stacks of the SEARCH network (Stations ALAC - JOVI). Stations are denoted in right upper corner. 

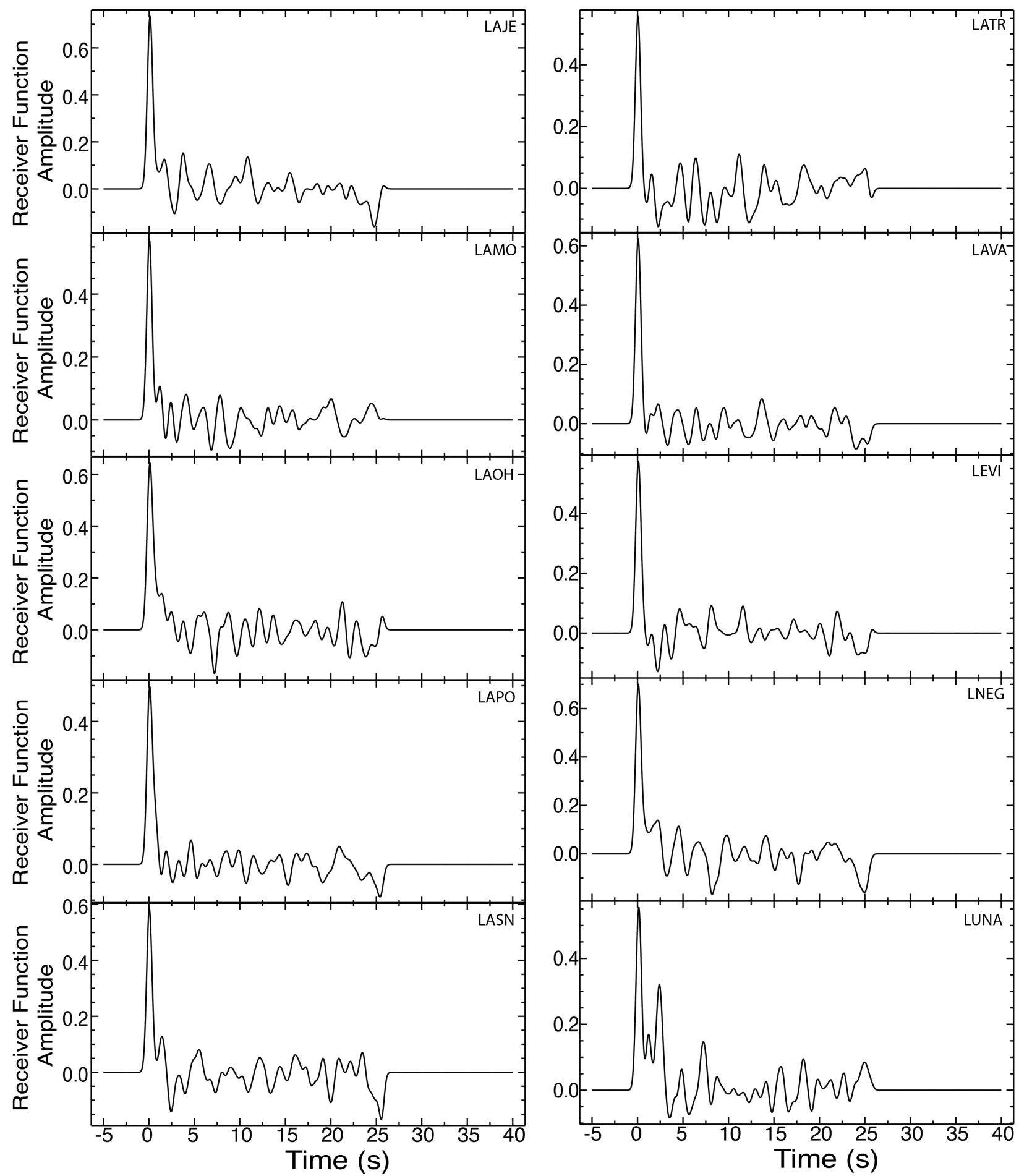

Figure S6. Receiver function stacks of the SEARCH network (Stations LAJE - LUNA). Stations are denoted in right upper corner. 

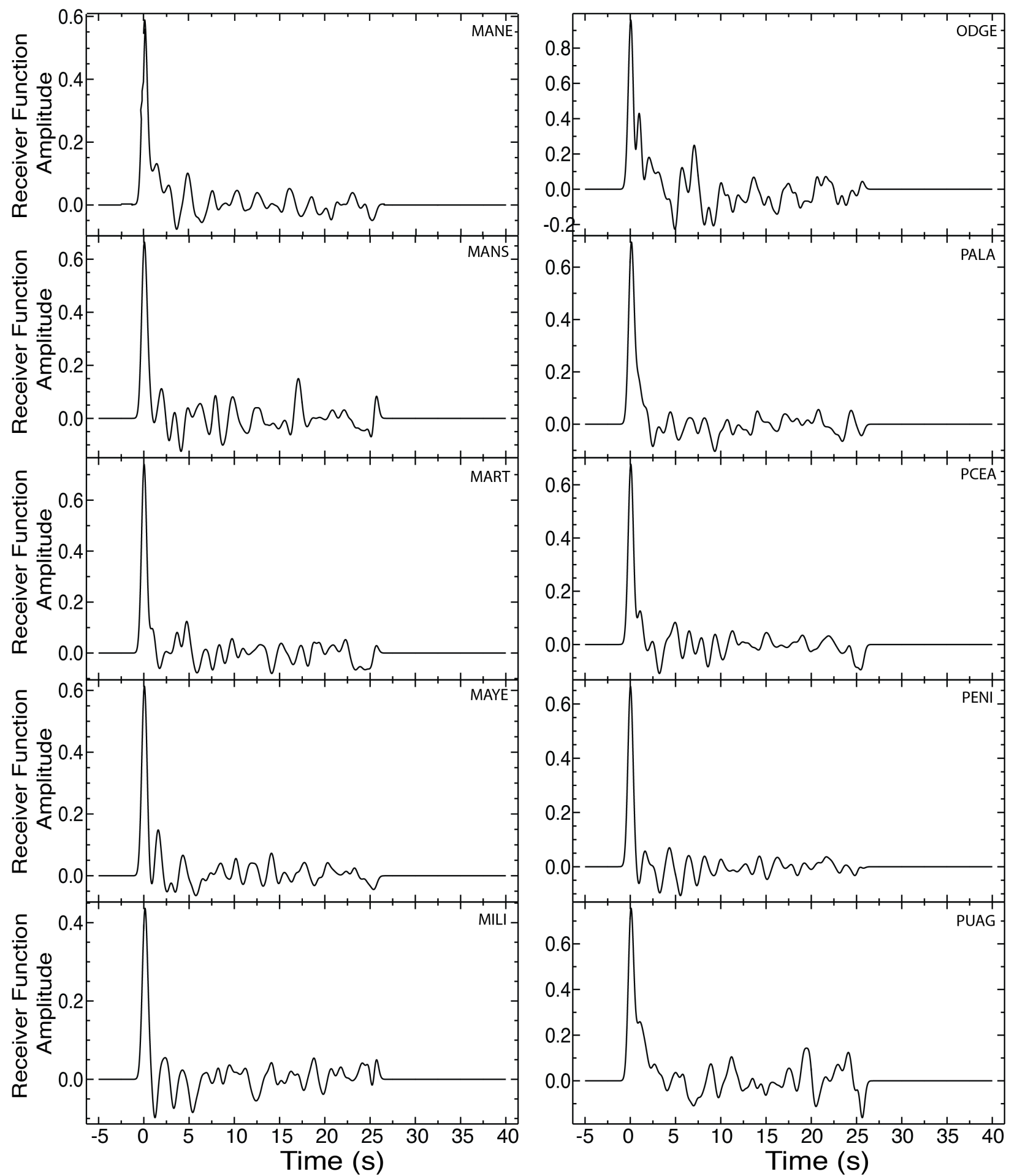

Figure S7. Receiver function stacks of the SEARCH network (Stations MANE - PUAG). Stations are denoted in right upper corner. 
Rodriguez, E.E., and Russo, R.M., 2019, Southern Chile crustal structure from teleseismic receiver functions:

Responses to ridge subduction and terrane assembly of Patagonia: Geosphere, v. 15, https://doi.org/10.1130/GES01692.1. Supplemental material: https://doi.org/10.1130/GES01692.S1
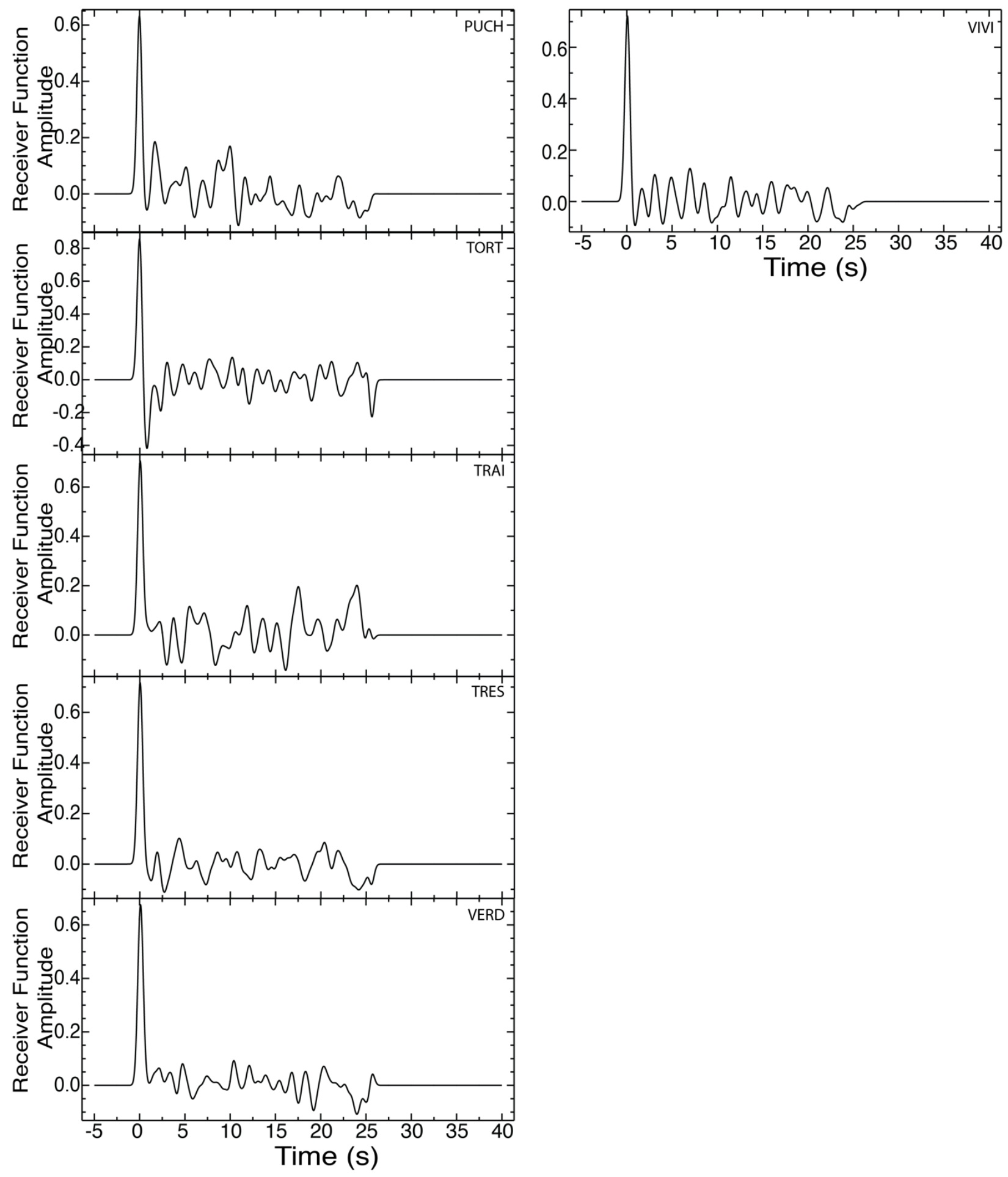

Figure S8. Receiver function stacks of the SEARCH network (Stations PUCH - VIVI). Stations are denoted in right upper corner. 

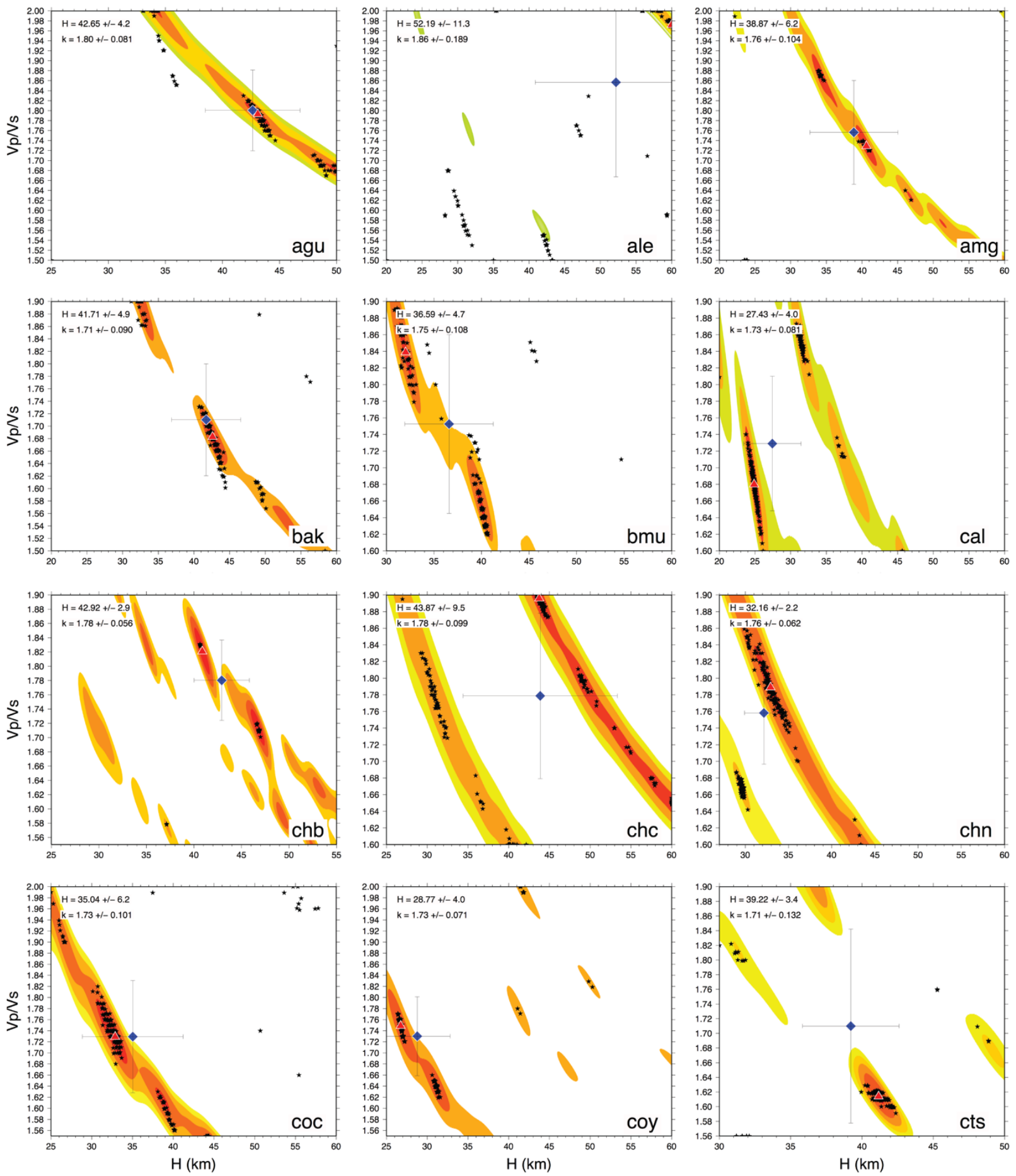

Figure S9. $H-k$ Stacking Results (Stations AGU - CTS). $H-k$ grid search (red triangle) and bootstrapping results (blue diamond with associated error bars) of the CRSP network stations AGU - CTS. Corresponding stations are denoted in the lower right and bootstrapping result in upper left of each figure. The black stars show the grid search result of each bootstrap run. 
Rodriguez, E.E., and Russo, R.M., 2019, Southern Chile crustal structure from teleseismic receiver functions:

Responses to ridge subduction and terrane assembly of Patagonia: Geosphere, v. 15, https://doi.org/10.1130/GES01692.1. Supplemental material: https://doi.org/10.1130/GES01692.S1
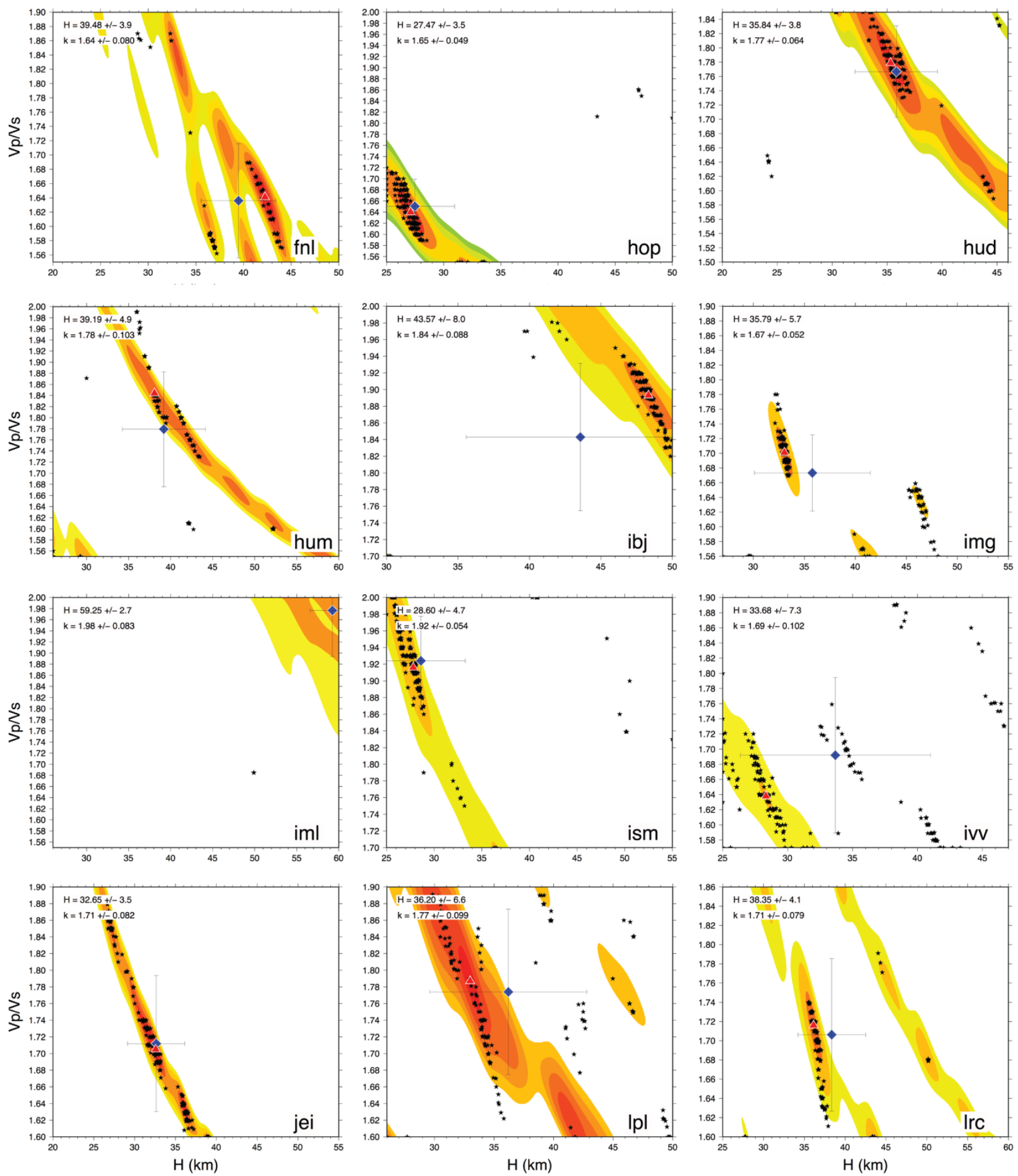

Figure S10. H-k Stacking Results (Stations FNL - LRC). H- $k$ grid search and bootstrapping results of the CRSP network stations FNL - LRC. Corresponding stations are denoted in the lower right and bootstrapping result in upper left of each figure. 
Rodriguez, E.E., and Russo, R.M., 2019, Southern Chile crustal structure from teleseismic receiver functions:

Responses to ridge subduction and terrane assembly of Patagonia: Geosphere, v. 15, https://doi.org/10.1130/GES01692.1. Supplemental material: https://doi.org/10.1130/GES01692.S1
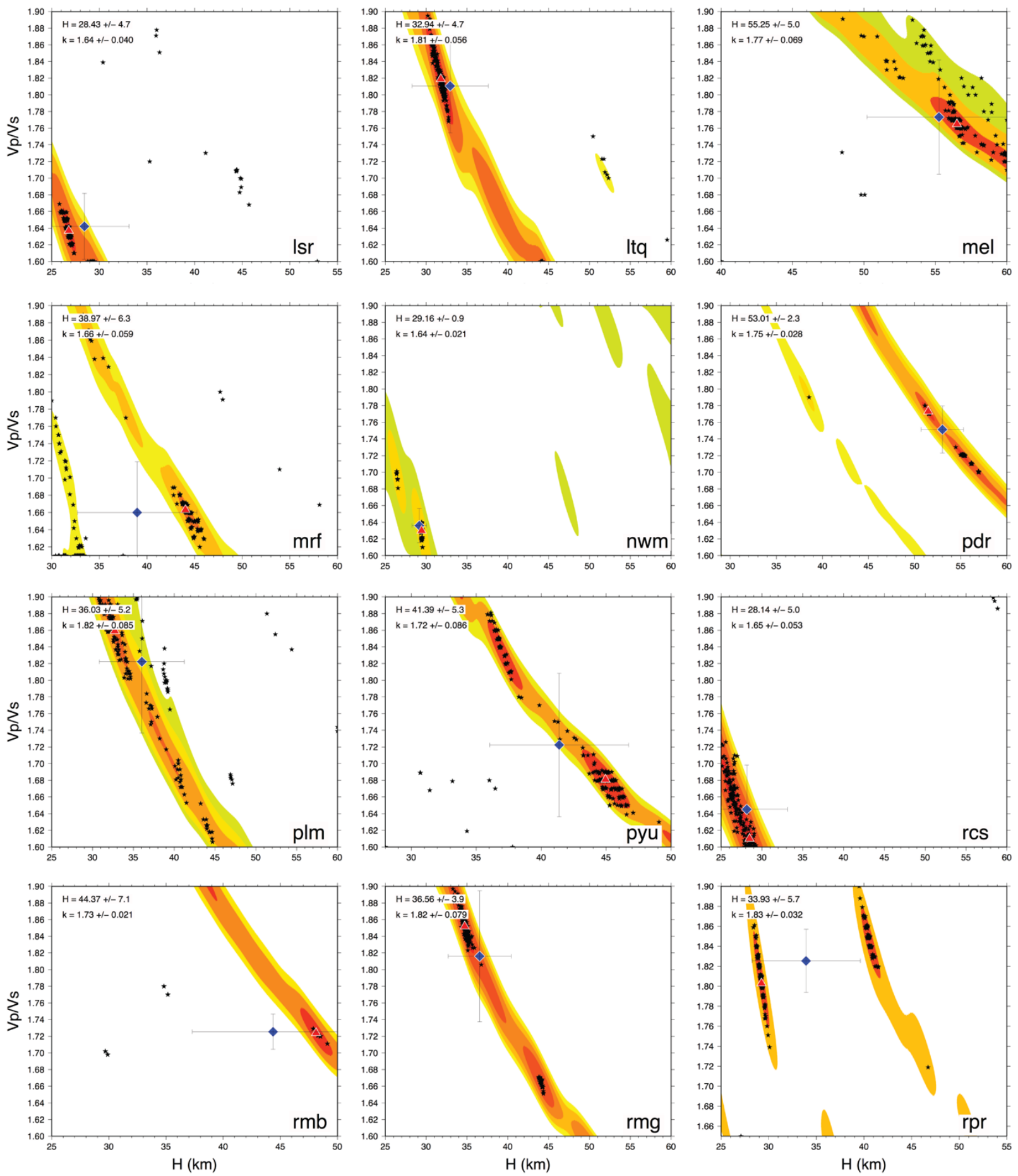

Figure S11. $H-k$ Stacking Results (Stations LSR - RPR). H- $k$ grid search and bootstrapping results of the CRSP network continued stations LSR - RPR. Corresponding stations are denoted in the lower right and bootstrapping result in upper left of each figure. 

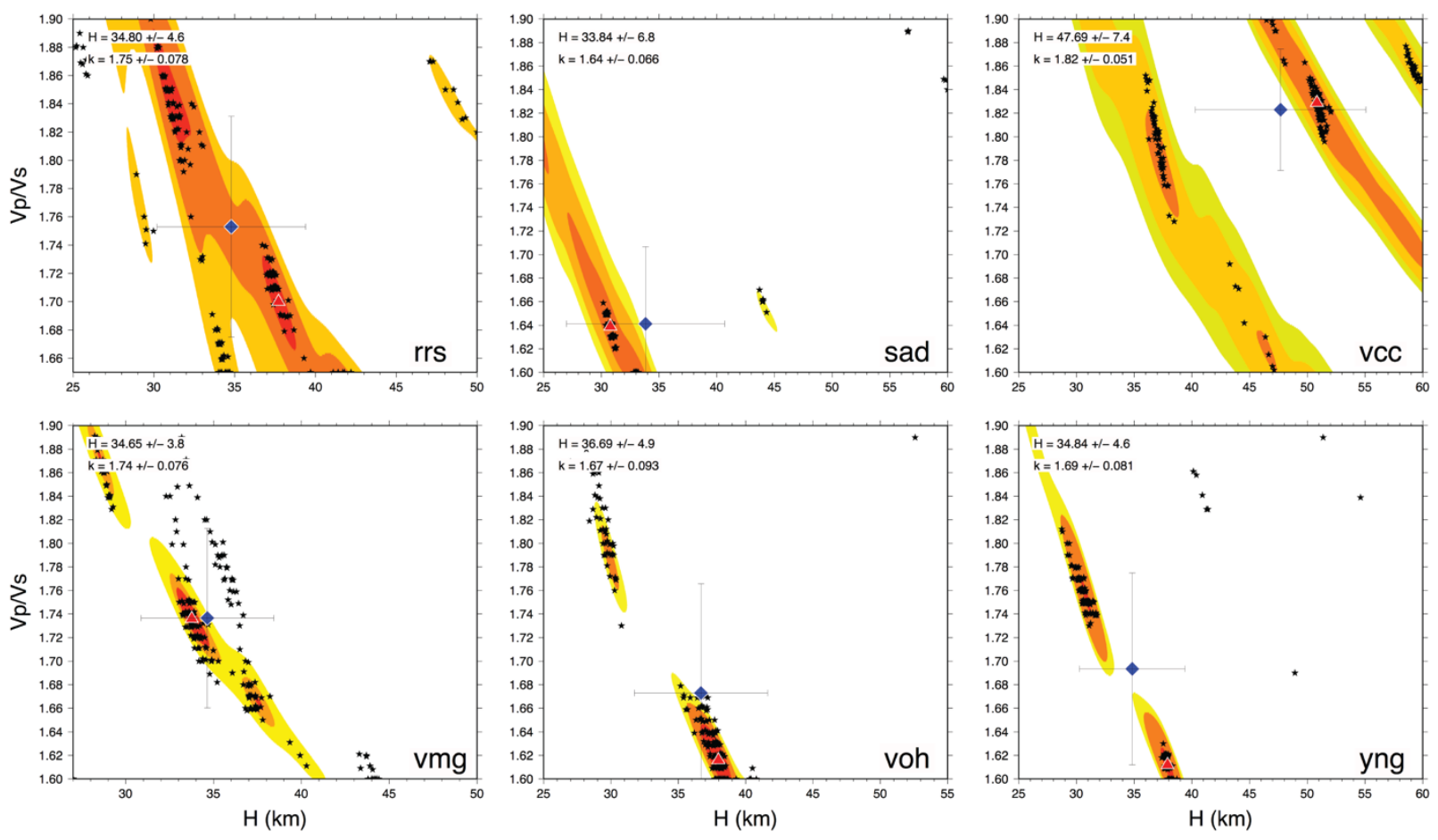

Figure S12. $H-k$ Stacking Results (Stations RRS - YNG). $H-k$ grid search and bootstrapping results of the CRSP network stations RRS - YNG. Corresponding stations are denoted in the lower right and bootstrapping result in upper left of each figure. 
Rodriguez, E.E., and Russo, R.M., 2019, Southern Chile crustal structure from teleseismic receiver functions:

Responses to ridge subduction and terrane assembly of Patagonia: Geosphere, v. 15, https://doi.org/10.1130/GES01692.1. Supplemental material: https://doi.org/10.1130/GES01692.S1
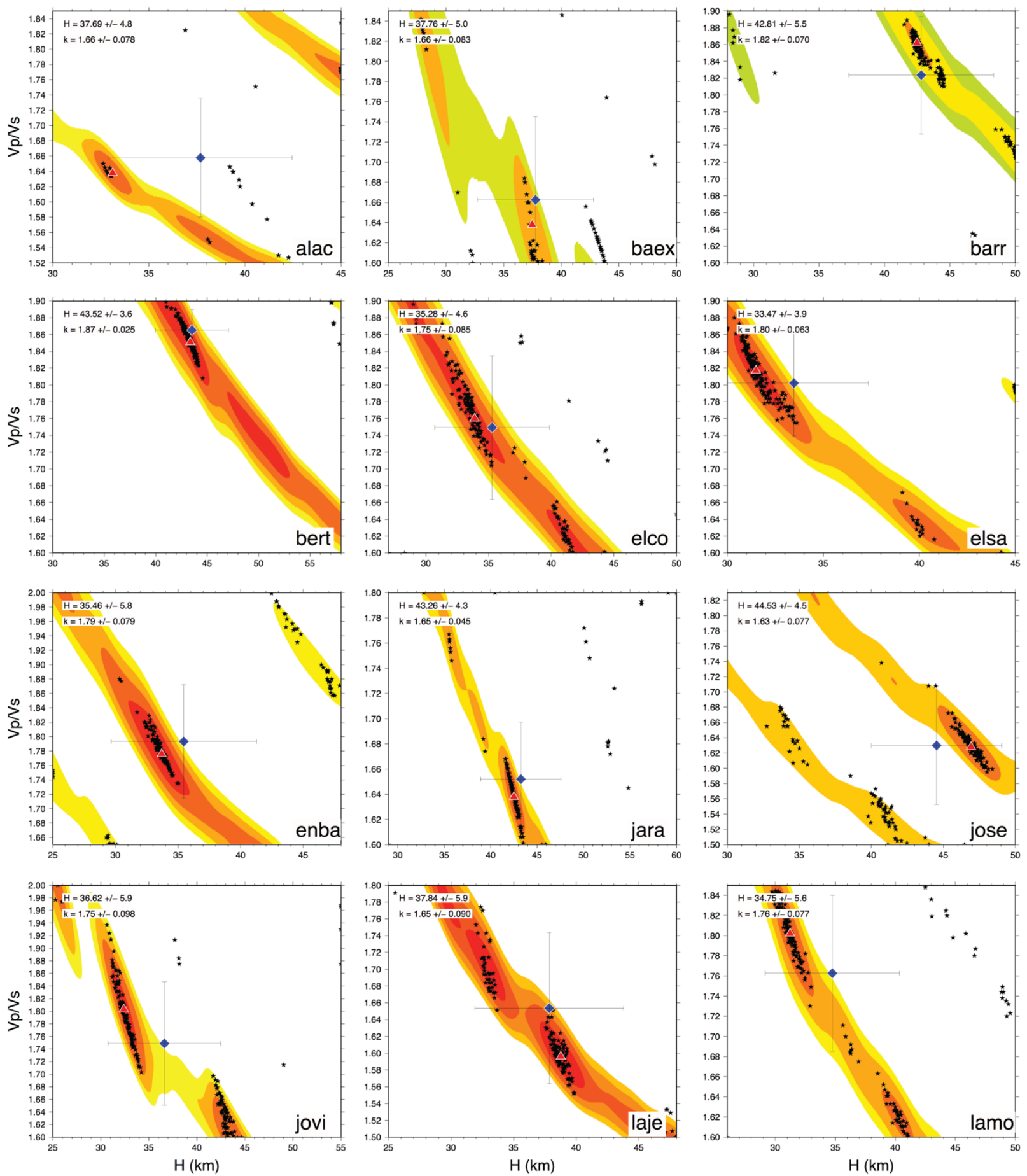

Figure S13. $H-k$ Stacking Results (Stations ALAC - LAMO). $H-k$ grid search and bootstrapping results of the SEARCH network stations ALAC - LAMO. Corresponding stations are denoted in the lower right and bootstrapping result in upper left of each figure. 
Rodriguez, E.E., and Russo, R.M., 2019, Southern Chile crustal structure from teleseismic receiver functions:

Responses to ridge subduction and terrane assembly of Patagonia: Geosphere, v. 15, https://doi.org/10.1130/GES01692.1. Supplemental material: https://doi.org/10.1130/GES01692.S1
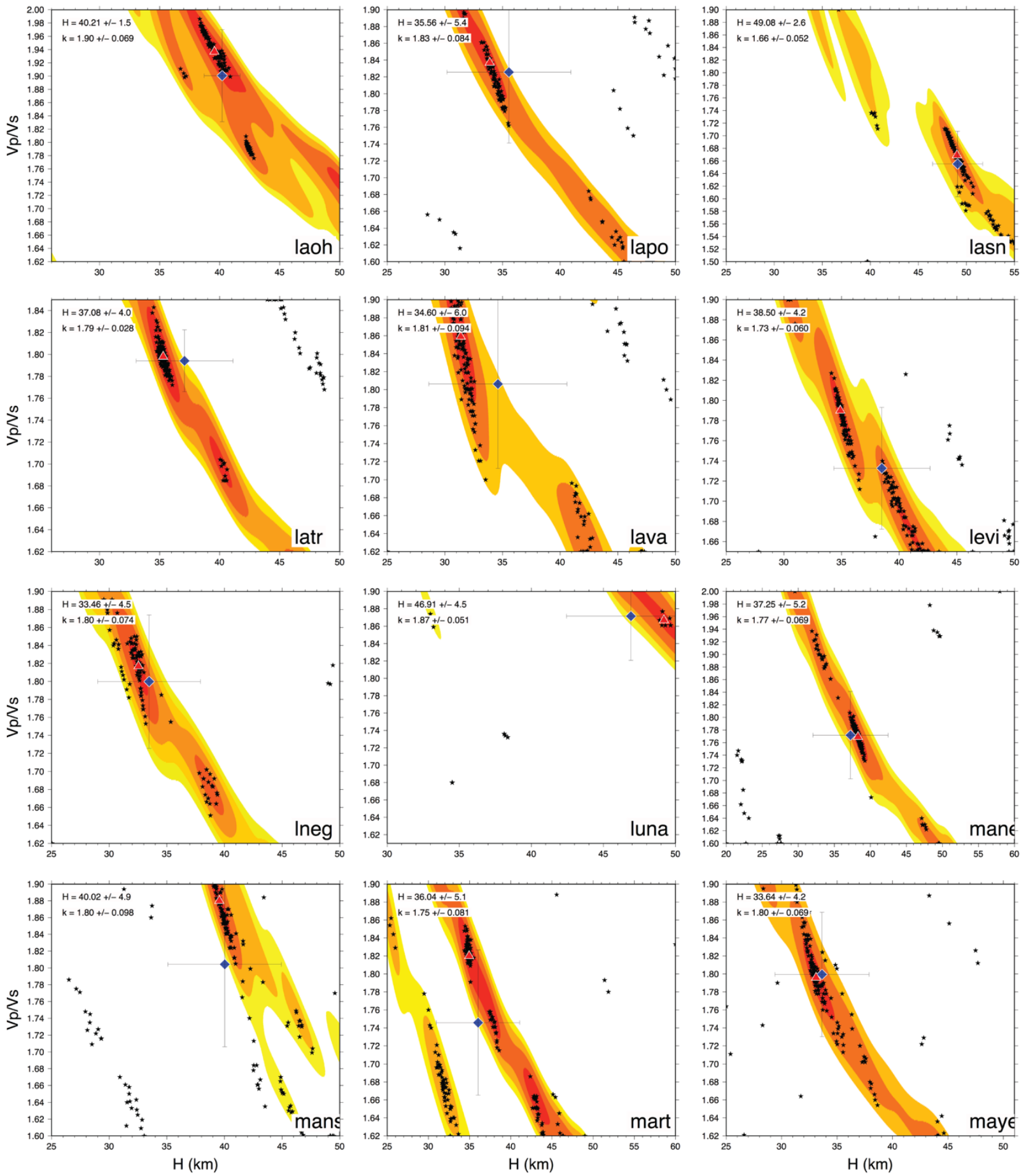

Figure S14. $H-k$ Stacking Results (Stations LAOH - MAYE). $H-k$ grid search and bootstrapping results of the SEARCH network stations LAOH - MAYE. Corresponding stations are denoted in the lower right and bootstrapping result in upper left of each figure. 
Rodriguez, E.E., and Russo, R.M., 2019, Southern Chile crustal structure from teleseismic receiver functions:

Responses to ridge subduction and terrane assembly of Patagonia: Geosphere, v. 15, https://doi.org/10.1130/GES01692.1. Supplemental material: https://doi.org/10.1130/GES01692.S1
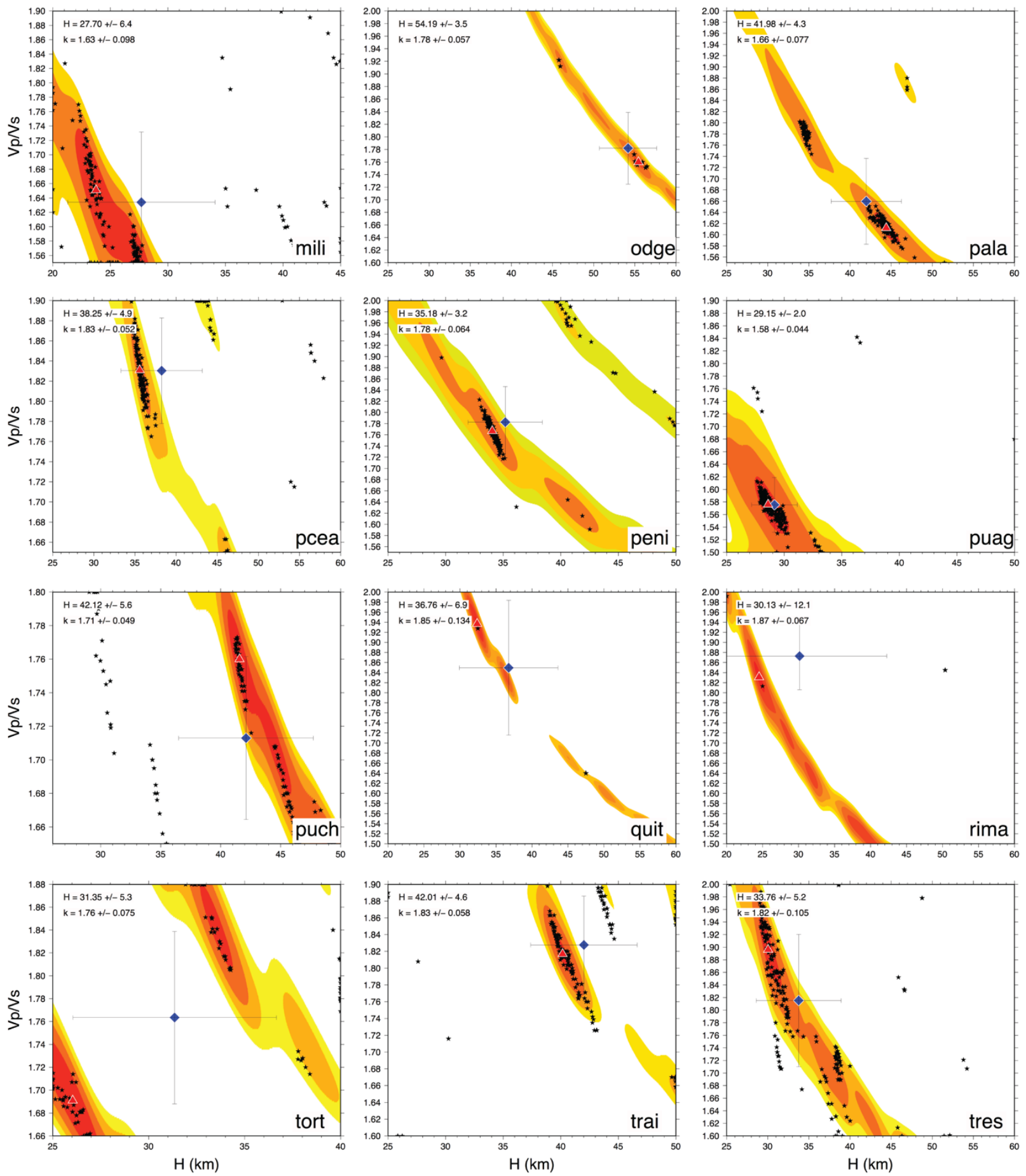

Figure S15. $H-k$ Stacking Results (Stations MILI - TRES). $H-k$ grid search and bootstrapping results of the SEARCH network stations MILI - TRES. Corresponding stations are denoted in the lower right and bootstrapping result in upper left of each figure. 

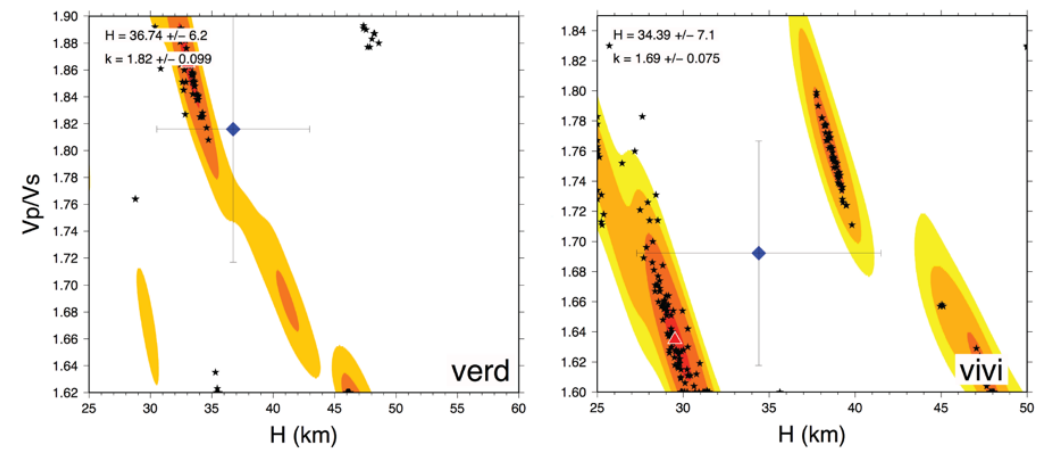

Figure S16. $H$ - $k$ Stacking Results (Stations VERD - VIVI). $H-k$ grid search and bootstrapping results of the SEARCH network stations VERD - VIVI. Corresponding stations are denoted in the lower right and bootstrapping result in upper left of each figure. 